\title{
In Memoriam: Professor Emeritus John D. Mackenzie
}

\section{Eric Bescher ${ }^{1} \cdot$ Bruce Dunn ${ }^{1}$}

Published online: 30 March 2020

C Springer Science+Business Media, LLC, part of Springer Nature 2020

John D. Mackenzie, professor emeritus of materials science and engineering at the UCLA Samueli School of Engineering who made pioneering contributions to glass and ceramics processing, passed away on February 19, after a short illness, he was 94 .

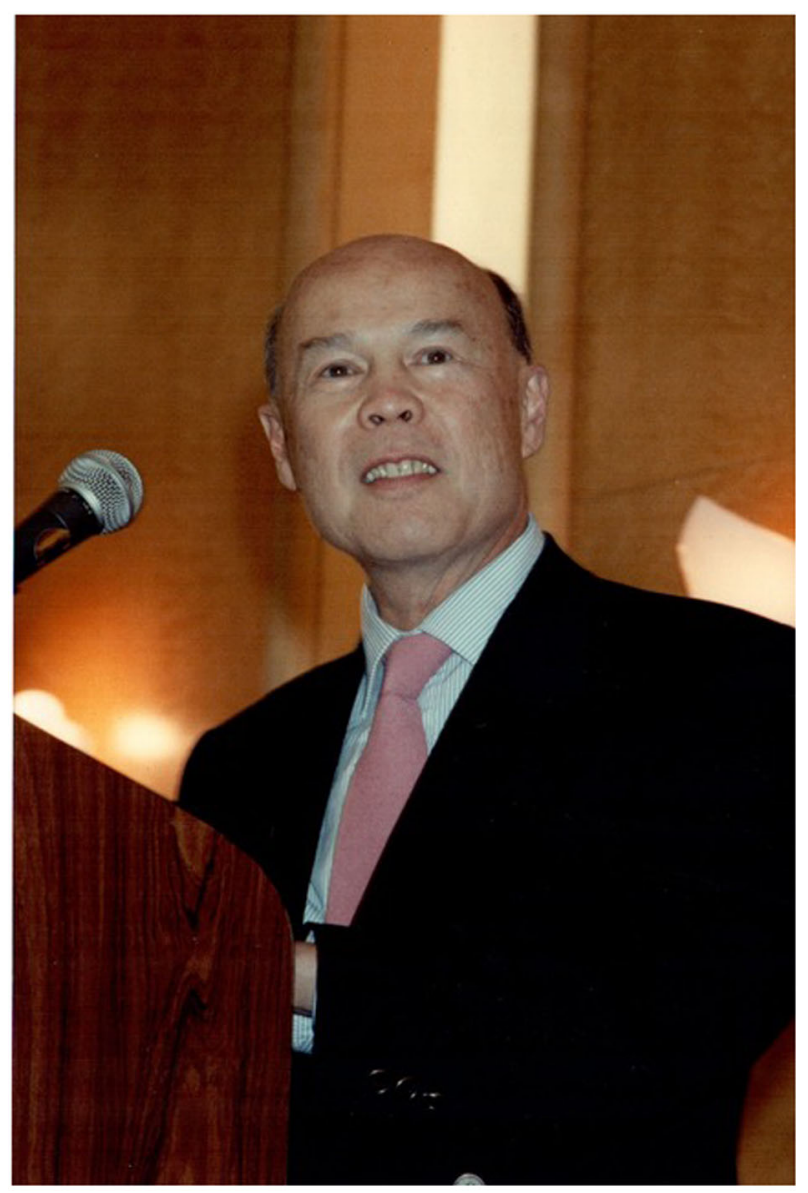

Eric Bescher

bescher@ucla.edu

1 UCLA, 6531 Boelter Hall, Los Angeles, CA 90095, USA
Known to friends and colleagues as "Doug," he joined the UCLA faculty in 1969 as a full professor, and was the inaugural holder of the Nippon Sheet Glass Company Chair in Materials Science.

Mackenzie earned his Bachelor's degree from Birkbeck College, in London, in 1952 and his doctorate from Imperial College London in 1954. He held post-doctoral and lecturer positions at Princeton University for 2 years, followed by another post-doctoral appointment at Cambridge University. He was a research scientist at General Electric Research Laboratory in Schenectady, New York from 1957 to 1963.

Mackenzie then turned to academia, joining Rensselaer Polytechnic Institute, in Troy, New York, as a professor, staying until 1969 when he joined UCLA as a professor of engineering.

At UCLA, Mackenzie supervised 32 Ph.D. students, 51 master's degree students, and some three dozen postdoctoral researchers and visiting scientists. He served as chair of the Materials Science and Engineering Department from 1979 to 1982.

Mackenzie retired from full-time teaching in 1994, but continued to conduct research and served for several years as an associate dean for research and planning.

He received numerous major international honors for his research, including election to the National Academy of Engineering in 1976 for "contributions to glass technology through application of principles of chemistry and physics" and the Centenary Award in 1991 from the Japanese Ceramics Society. Mackenzie was a fellow of the British Royal Society of Chemistry and the American Ceramic Society.

In addition to authoring more than 300 publications, Mackenzie was co-editor of ten books and was awarded 15 U.S. patents. He founded the Journal of Non-Crystalline Solids in 1969 and was its editor-in-chief for 20 years. He was instrumental in the founding of the Journal of Sol-Gel Science and Technology, and the International Sol-Gel Society. He was the recipient of the 2019 L. David Pye Lifetime Achievement Award, from the American Ceramic Society, for his contributions to the field. 
Mackenzie was preceded in death by his wife of 65 years, Jennifer, who passed on October 2, 2019. He is survived by his children Timothy, Andrea and Peter; his grandchildren Jacqueline Mackenzie, Gwyneth Mackenzie, and Kiana Martin; his children's spouses Liane Curtis, Jenni
Martin, and Loretta Mackenzie; as well as his brother Eric Mackenzie, and wife Genevieve Mackenzie.

Donations may be made to the Professor John D. Mackenzie Scholarship in Materials Science at UCLA. 